\title{
A Paz na Jurisprudência do Tribunal Internacional de Justiça*
}

Mateus Kowalski ${ }^{1}$

\section{Resumo}

O propósito primeiro que presidiu à criação das Nações Unidas foi a paz. A Carta das Nações Unidas estabelece no preâmbulo, bem como nos seus artigos $1 .^{\circ}$ e $2 .^{\circ}$, um conjunto de objectivos e princípios que servem como linhas orientadoras para a acção das Nações Unidas e dos seus membros. A paz é apresentada como o objectivo estruturador e aglutinador de todos os outros. A paz proclamada na Carta é, pois, uma noção de conteúdo amplo que não se resume à mera ausência de guerra. Antes, ela é multidimensional abarcando diversos elementos de acção necessários para a manutenção da sua condição intrínseca, tais como a coexistência pacífica, a solução pacífica de controvérsias, a autodeterminação, o desenvolvimento, a promoção e respeito pelos direitos humanos, a acção colectiva ou o respeito pelas soberanias. O Tribunal Internacional de Justiça é o principal órgão judicial das Nações Unidas, integrando, pois, a estrutura da organização. Assim sendo, a actividade do Tribunal está, também ela, devota à prossecução das atribuições gerais das Nações Unidas, incluindo, em primeiro lugar, a paz conforme consagrada na Carta. O presente estudo pretende, assim, analisar o contributo da actividade do Tribunal Internacional de Justiça para a paz. Num primeiro momento procurar-se-á debater a função do Tribunal contextualizando-o no discurso da paz pelo Direito. Depois, proceder-se-á à análise de algumas decisões do Tribunal procurando identificar construções jurisprudenciais marcantes de elementos da paz. Da análise feita conclui-se que aquelas construções, inscrevendo-se na tradição idealista-liberal de paz, não deixam de ser perpassadas por afloramentos do realismo. Um sintoma das dinâmicas que informam as Nações Unidas.

* Recebido em 26.09.2010.

Aprovado em 18.11.2010.

1 Doutorando em Política Internacional e Resolução de Conflitos na Universidade de Coimbra, Mestre em Direito Internacional Público pela Universidade de Lisboa e Licenciado em Direito pela Universidade de Coimbra. O autor agradece o apoio que lhe é conferido pela Fundação Calouste Gulbenkian para a realização do programa de Doutoramento. O autor pode ser contactado através do e-mail mateuskowalski@ces. uc.pt. 
Palavras-chave: Paz. Tribunal Internacional de Justiça. Paz pelo Direito. Carta das Nações Unidas.

\section{Introdução}

O propósito primeiro que presidiu à criação das Nações Unidas foi a paz. O texto da Carta, apesar de escrito para o futuro, está ainda agarrado a um passado que se quer irrepetível, encerrando um conjunto de lições da história que os seus redactores dizem ter aprendido. São afirmadas as bases da nova ordem internacional, assente em objectivos e princípios comuns que deverão reger as relações internacionais no futuro que começa com o fim da Segunda Grande Guerra.

A Carta estabelece no preâmbulo, bem como nos seus artigos $1 .^{\circ}$ e $2 .^{\circ}$, um conjunto de objectivos e princípios que servem como linhas orientadoras para a acção das Nações Unidas e dos seus membros. A paz é apresentada como o objectivo estruturador e aglutinador de todos os outros (LACHS, 1991; WOLFRUM, 2002). A paz proclamada na Carta é, pois, uma noção ampla que não se resume à mera ausência de guerra. Antes, ela é multidimensional abarcando diversos elementos de acção necessários para a manutenção da sua condição intrínseca (WOLFRUM, 2002), tais como a coexistência pacífica, a solução pacífica de controvérsias, a autodeterminação, o desenvolvimento, a promoção e respeito pelos direitos humanos, a acção colectiva ou o respeito pelas soberanias. A Carta consagra, pois, uma paz de carácter indivisível (DUPUY, 1991).

Esta noção estruturada de paz foi sendo progressivamente assumida e densificada, quer do ponto de vista de cada um dos elementos que a compõem quer no que respeita à sua construção teórica. São disso exemplo a evolução em domínios como os direitos humanos, o desenvolvimento ou o direito à autodeterminação, bem como a elaboração de documentos como a resolução relativa à Proclamação do Ano Internacional da Paz (UNITED NATIONS, 1985), a Agenda para a Paz (UNITED NATIONS, 1992) ou a Declaração e Programa de Acção sobre uma Cultura de Paz (UNITED NATIONS, 1999). 
O Tribunal Internacional de Justiça é o principal órgão judicial das Nações Unidas, integrando, pois, a estrutura da organização. Assim sendo, a actividade do Tribunal está, também ela, devota à prossecução das atribuições gerais das Nações Unidas, desde logo a paz conforme consagrada na Carta.

O presente estudo pretende, assim, analisar o contributo da actividade do Tribunal Internacional de Justiça para a paz. Num primeiro momento procurar-se-á debater a função do Tribunal contextualizando-o no discurso da paz pelo Direito. Depois, proceder-se-á ao estudo de algumas decisões do Tribunal procurando identificar construções jurisprudenciais marcantes de elementos da paz. Finalmente, será analisada a presença das narrativas idealista e realista na actividade do Tribunal.

\section{Tribunal Internacional de Justiça e a teoria da paz pelo Direito}

Apesar de se inserir na estrutura de uma organização política, o Tribunal encontra-se numa posição independente. Não é composto por representantes dos Estados Membros e deve decidir, como qualquer órgão judicial, exclusivamente em aplicação do Direito, sendo impermeável, em princípio, a qualquer circunstância de ordem política. A função do Tribunal é, pois, contribuir para a paz através da solução judicial de controvérsias entre Estados (HIGGINS, 2008).

Ora, o contributo do Tribunal para a paz é uma ideia que encontra acolhimento na narrativa da paz pelo Direito. A perspectiva de que a paz pode ser normativizada e, portanto, organizada e mantida pelo Direito ganha uma clara expressão após o Tratado de Versalhes, em especial com a adopção do Pacto da Sociedade das Nações. Após o fracasso da Sociedade das Nações, a adopção da Carta das Nações Unidas reanimou a aspiração da paz pelo Direito assente, agora, numa instituição aparentemente aperfeiçoada e com maior poder normativo, e portanto mais capaz de garantir a paz internacional. Alguns autores chegam mesmo a nomear a Carta como constituição da comunidade internacional (FASSBENDER, 1998; KOWALSKI, 2009). 
Hans Kelsen é uma das maiores referências da teoria da paz pelo Direito. Cultor de um normativismo puro e acérrimo defensor do primado do Direito Internacional, Kelsen identificava o Estado como sendo, em última análise, um ordenamento jurídico. O seu pacifismo jurídico levou-o a defender que o Direito é a única via para atingir a paz universal. Na sua concepção, a paz deveria assentar em instituições internacionais e, em última análise, ser organizada no âmbito de uma confederação de Estados ou mesmo, posteriormente, no âmbito de um Estado Federal Mundial (KELSEN, 2008).

As Nações Unidas, cujo objectivo seria a «paz mundial» (KELSEN, 1950: 19), e em concreto o Tribunal Internacional de Justiça, representam no discurso de Kelsen elementos fundamentais da prossecução da paz pelo Direito. O projecto de Kelsen para uma "Liga Permanente para a Manutenção da Paz" confere um papel central à função judicial que deve ser capaz de se impor ao poder executivo. Para garantir a paz seria necessário que existisse um tribunal internacional de justiça que resolvesse os litígios entre os Estados e que fosse dotado de mecanismos realmente eficazes para a execução das suas decisões. Afirmava Kelsen que enquanto tal não se verificar «qualquer progresso no sentido da pacificação do mundo será absolutamente de excluir» (KELSEN, 2008, p. 14).

A teoria da paz pelo Direito e o normativismo puro de Kelsen, gozam de méritos que lhe devem ser reconhecidos, designadamente no que respeita ao seu contributo para o desenvolvimento do Direito Internacional, bem como a defesa de ideias como a elevação dos indivíduos à condição de sujeitos de Direito Internacional, a criação de tribunais penais internacionais, ou até, no tema que nos ocupa, a relevância que confere ao Tribunal como elemento essencial na solução pacífica de controvérsias entre os Estados.

Estes méritos não ofuscam, porém, as críticas que lhe são merecidas. Desde logo, porque aquela narrativa assenta num normativismo dogmático e redutor, em que a realidade é construída em função de postulados teóricos. Pelo contrário, a construção do Direito e a sua aplicação devem assentar num contexto político, económico e social, para além de deverem assumir necessariamente um carácter evolutivo. Por outro lado, o total abandono do Estado em favor da centralização 
da governação em instituições internacionais globais não deve deixar de ser vista com algum cuidado. Precisamente, o período que medeia as duas grandes guerras, marcado pelo desaire da Sociedade das Nações e, depois, com as Nações Unidas, a Guerra Fria e a conjuntura actual são referidos como exemplos da cautela que deverá existir quando se pretendam depositar ilimitadas esperanças de paz universal no Direito Internacional e nas instituições internacionais (DELAHUNTY; YOO, 2008).

Danilo Zolo tem sido um dos autores que, de forma aturada, tem manifestado a sua discordância relativamente à teoria da paz pelo Direito, incluindo o pacifismo jurídico de Kelsen. Zolo rejeita aquilo a que apelida de cosmopolitismo jurídico (ZOLO, 1997). Argumenta que as instituições internacionais são inevitavelmente dominadas pelas grandes potências que não se encontram submetidas a um efectivo controlo jurisdicional. O Direito Internacional, por si, não conseguiria superar esta realidade. Por outro lado, o autor desconfia da real eficácia que um tribunal internacional de justiça possa ter, quando, por um lado, não pode controlar a acção do Conselho de Segurança e, por outro, a execução das suas sentenças assenta na mera vontade do Conselho de Segurança. O entusiasmo de Kelsen a este respeito seria, pois, demasiado optimista (ZOLO, 1998).

Ora, é verdade que o projecto da paz pelo Direito se rege por pressupostos que acabam por se tornarem numa visão redutora e até autolimitativa da construção da ordem internacional, composta por insuficiências que podem ser instrumentalizadas. Contudo, não será menos verdade que para além de contribuir para a paz através do exercício da sua função de solução jurisdicional de conflitos, o Tribunal tem ido um papel relevante na elaboração de construções jurisprudenciais de elementos da paz.

\section{Construção de elementos da paz pelo Tribunal Internacional de Justiça}

No exercício da sua actividade, no âmbito das suas competências contenciosa e consultiva, o Tribunal tem formulado construções jurisprudenciais sobre elementos da paz. Serão, neste ponto, analisados alguns casos que, pela sua di- 
mensão histórica, pelo seu alcance, bem como pela sua relevância na delimitação conceptual daqueles elementos, atestam esta dimensão da sua actividade.

\subsection{Soberania}

A soberania é um elemento fundamental caracterizador do Estado. Tendo vindo, porém, a perder o seu carácter clássico absoluto, a soberania estadual continua a ser uma afirmação da igualdade soberana dos Estados e, portanto, da sua independência. O Tribunal Internacional de Justiça teve já oportunidade de se pronunciar sobre questões relacionadas com a soberania.

O caso Estreito de Corfu, submetido em 1947 e que opunha o Reino Unido à Albânia, foi o primeiro caso sobre o qual o Tribunal Internacional de Justiça se pronunciou. A 22 de Outubro de 1946, dois navios de guerra do Reino Unido embateram em minas no estreito de Corfu quando navegavam em águas territoriais albanesas. Na sequência, o Reinou Unido, nos dias 12 e 13 de Novembro de 1946 empreendeu operações de desminagem em águas territoriais albanesas, não autorizadas pela Albânia.

O Reino Unido alegou que se tratava de uma nova forma de intervenção para permitir que o Estado que sofreu o dano pudesse recolher provas para apresentar ao Tribunal. Depois, reivindicou que se tratava de uma acção de "autoprotecção".

O Tribunal rejeitou estes argumentos do Reino Unido. Primeiro afirmou que uma intervenção daquele tipo seria a expressão de uma "política de força que no passado deu origem a abusos graves» (INTERNATIONAL COURT OF JUSTICE,1949, p. 35). Depois fez uma declaração de princípio referindo que «entre Estados independentes, o respeito pela soberania territorial é um elemento fundamental das relações internacionais» (INTERNATIONAL COURT OF JUSTICE, 1949, p. 35). O Tribunal decidiu, assim, que o Reino Unido violou a soberania da Albânia aquando das operações de desminagem de Novembro. 


\subsection{Dimensão institucional}

Para operacionalizar o seu conteúdo, a Carta institui a organização internacional "Nações Unidas". Será ela o centro da acção colectiva para a consecução dos objectivos proclamados pela Carta. O Tribunal Internacional de Justiça tem contribuído para o reforço da autonomia das Nações Unidas e para a sua densificação institucional.

A Assembleia Geral das Nações Unidas solicitou em 1948 ao Tribunal um parecer consultivo sobre se as Nações Unidas teriam capacidade jurídica para apresentar uma reclamação relativamente a danos sofridos por agentes seus no decurso de uma missão e pelos quais um Estado fosse responsável. No parecer Reparação de Danos, ao analisar a questão, e apesar de não existir disposição concreta nesse sentido, o Tribunal considerou que as Nações Unidas têm personalidade jurídica internacional, sendo esta oponível a todos os Estados independentemente do reconhecimento (INTERNATIONAL COURT OF JUSTICE, 1949). A opinião do Tribunal, considerada à data como audaz, contribuiu para o reforço do estatuto internacional e independente das Nações Unidas.

Num outra situação, no caso Lockerbie, o Conselho de Segurança havia solicitado à Líbia que entregasse os dois presumíveis responsáveis pelo atentado contra um avião da Pan Am que se despenhou em Lockerbie, na Escócia, decidindo que o não cumprimento com a resolução constituiria uma ameaça à paz. A Líbia submeteu o caso ao Tribunal, contra o Reino Unido e os Estados Unidos da América (EUA), solicitando a aplicação de medidas provisórias arguindo que tinha cumprido com as suas obrigações de julgar os responsáveis pelo atentado, ao abrigo da Convenção para a Eliminação de Actos Ilícitos Contra a Segurança da Aviação Civil, adoptada em Montreal, a 23 de Setembro de 1971. O Tribunal afirmou então que nos termos do artigo 103 da Carta, as obrigações resultantes de uma resolução do Conselho de Segurança prevalecem sobre as suas obrigações decorrentes de qualquer outra convenção internacional, incluindo a Convenção de Montreal (INTERNATIONAL COURT OF JUSTICE, 1998). A afirmação é poderosa, daqui se podendo retirar que as obrigações que resultem da Carta e das deliberações vinculativas dos seus órgãos prevalecerão, igualmente, sobre as deliberações vinculativas dos órgãos de outras organizações internacionais. 
Por outro lado, pela primeira vez na sua história, ao recusar a aplicação das medidas provisórias pedidas pela Líbia, o Tribunal acabou por assumir que tinha competência para decidir sobre uma questão em que poderia ser chamado a apreciar uma resolução do Conselho de Segurança tomada ao abrigo do capítulo VII. Com a entrega dos suspeitos, em 1999, o litígio foi entretanto resolvido. No entanto, ficou aberta a porta para a afirmação da competência do Tribunal para controlar, a título incidental, o exercício do poder pelo Conselho de Segurança.

\subsection{Proibição da ameaça ou uso da força}

A coexistência pacífica que a Carta almeja integra a questão da prevenção da guerra. O princípio da proibição da ameaça e do uso da força é, neste contexto, um seu elemento lógico e essencial (RANDELZHOFER, 2002).

No caso Actividades Militares, que opôs a Nicarágua aos EUA, submetido em 1984, o Tribunal teve a oportunidade de se pronunciar sobre o princípio da proibição da ameaça ou uso da força. A Nicarágua acusou os EUA de terem usado força militar contra a Nicarágua e de terem interferido nos seus assuntos internos. Designadamente, a Nicarágua alegou que os EUA atacaram o território da Nicarágua por diversas vezes entre 1983 e 1984, e que treinaram, equiparam e financiaram o movimento dos "Contras" que se opunha à Frente Sandinista de Libertação Nacional que então formava o Governo.

Por sentença de 1986, o Tribunal deu razão à Nicarágua. O Tribunal afirmou que os EUA, ao armarem e treinarem os "Contras", violaram o princípio da proibição da ameaça ou uso da força (INTERNATIONAL COURT OF JUSTICE, 1986). Considerou, no entanto, que o financiamento dos "Contras" não pode ser considerado como uma violação daquele princípio. Por outro lado, o Tribunal admitiu que aqueles actos praticados pelos EUA poderiam ser lícitos se justificados pelo exercício da legítima defesa. Entendeu, porém, que os seus pressupostos não encontravam reunidos no caso. Esta sentença contribui, assim, para a afirmação do princípio da proibição da ameaça ou uso da força e para a delimitação do seu conteúdo. 


\subsection{Direitos humanos}

A Carta das Nações Unidas não incorpora um catálogo de direitos fundamentais. No entanto, os direitos humanos são reconhecidos como fundamentais pela Carta. A prática foi-se encarregando de, lentamente, ir desenvolvendo aquele que é um dos mais relevantes domínios da actuação das Nações Unidas. Assim, nos últimos anos, também o Tribunal Internacional de Justiça se tem pronunciado sobre questões envolvendo direitos humanos.

No caso Actividades Armadas no Território do Congo o Tribunal Internacional de Justiça foi chamado a pronunciar-se sobre os actos de agressão cometidos pelas forças do Uganda em território do Congo nos anos de 1998 e 1999. No que à matéria de direitos humanos diz respeito, o Tribunal começou por afirmar que actos de violência armada podem redundar na violação de direitos humanos (INTERNATIONAL COURT OF JUSTICE, 2005). Considerou, assim, que as forças do Uganda cometeram em território do Congo actos violadores de direitos humanos, designadamente assassínio, tortura, incitamento ao conflito étnico ou o treino de crianças soldado. Por outro lado, o Tribunal considerou que recaía sobre o Uganda, enquanto potência ocupante, a obrigação de tomar medidas que garantissem o respeito pelos direitos humanos.

O Tribunal fez uma afirmação jurídica de grande relevo, ao entender que num conflito armado se aplica quer o Direito Internacional Humanitário quer também o Direito Internacional dos Direitos Humanos, tomando assim uma posição forte numa questão controversa e de enorme impacto na regulação dos conflitos armados. Ademais, considerou que as convenções sobre direitos humanos se aplicam relativamente aos actos cometidos por um Estado no exercício da sua jurisdição mesmo fora do seu próprio território.

\subsection{Autodeterminação}

A ideia da autodeterminação dos povos expressamente consagrada na Carta era inicialmente um conceito essencialmente político e de conteúdo diferente daquele que foi ganhando consistência nos anos sessenta. O Tribunal Internacional 
de Justiça desempenhou um papel fundamental no reconhecimento da autodeterminação como um direito.

O Conselho de Segurança solicitou em 1970 um parecer ao Tribunal relativamente às consequências jurídicas para os Estados pela presença continuada da África do Sul na Namíbia. O mandato para administração da Namíbia havia sido conferido à África do Sul ao tempo da Sociedade das Nações. Desde a sua dissolução, em 1946, o estatuto do território foi objecto de longas discussões nas Nações Unidas.

No parecer Consequências Jurídicas o Tribunal foi da opinião que a presença da África do Sul na Namíbia era ilícita, e que aquele Estado deveria retirar a sua administração e pôr termo à ocupação do território (INTERNATIONAL COURT OF JUSTICE, 1971). No seu parecer, o Tribunal considerou que o direito à autodeterminação conforme consagrado na Carta aplica-se a todos os territórios não-autónomos.

No parecer Saara Ocidental, sobre o estatuto daquele território, o Tribunal confirmou o seu entendimento relativamente ao direito à autodeterminação, afirmando que o povo do Saara Ocidental gozava daquele direito. Acrescentou, ainda, que a «aplicação do direito à autodeterminação requer a expressão livre e genuína da vontade dos povos em causa» (INTERNATIONAL COURT OF JUSTICE, 1975, p. 32).

\section{Realismo e idealismo na paz do Tribunal}

A tradição realista das Relações Internacionais oferece uma visão de paz negativa, assente numa ordem westfaliana de Estados soberanos que desconfia das instituições internacionais. Nesta agenda, a paz, que é a dos vencedores, não pode ser uma paz sustentável e duradoura. Já a tradição idealista faz apelo a uma noção de paz positiva, vivendo a esperança de que a guerra pode ser erradicada. A paz idealista assenta na organização dos Estados em instituições internacionais, bem como na consideração do indivíduo e dos seus direitos. 
A actividade do Tribunal para a paz inscreve-se de forma mais evidente na tradição idealista, em especial na concepção de paz liberal. Desde logo, porque é um órgão das Nações Unidas, organização de estrutura complexa que detém amplos poderes e um vasto leque de atribuições, e que prossegue uma paz positiva (WOLFRUM, 2002). O sistema das Nações Unidas pode mesmo ser classificado como o mais sofisticado instrumento da paz liberal (RICHMOND, 2008). Por outro lado, o facto de o Tribunal ser um órgão composto por juízes independentes e com capacidade de emitir decisões obrigatórias para os Estados parte num litígio, reforça a sua dimensão institucional. Ainda, sendo a sua actividade devota à resolução de litígios em aplicação do Direito Internacional, não deixa de se inscrever na perspectiva kantiana que pretende as normas internacionais como forma de evitar a violência e, de um ponto de vista mais geral, na ambição do progressivo desenvolvimento do Direito Internacional.

As construções jurisprudenciais de elementos da paz analisadas encerram expressões da tradição liberal. As afirmações do Tribunal em favor do reforço da dimensão institucional das Nações Unidas e das suas dinâmicas internas inserem-se nesta concepção de paz liberal. No parecer Reparação de Danos o Tribunal afirmou de forma audaz a personalidade jurídica das Nações Unidas. Já no caso Lockerbie, o Tribunal reconheceu uma quase superioridade normativa da ordem jurídica das Nações Unidas. Por outro lado, afirmou que a legalidade da acção do Conselho de Segurança, órgão que acolhe o poder dos Estados na organização, deve ser apreciada à luz da Carta, e que o Tribunal poderá ser o último defensor da legitimidade do sistema. De igual modo, o contributo para a delimitação do princípio da proibição da ameaça ou uso da força no caso Actividades Militares, para além de se inserir numa lógica de atribuição do monopólio do poder bélico público às Nações Unidas (BAPTISTA, 2003), salvaguarda, igualmente as situações de legítima defesa na linha da perspectiva kantiana. Num outro registo, a ideia de que a paz concerne também aos indivíduos, e não apenas aos Estados, é uma expressão da paz liberal. Apesar do âmbito subjectivo da sua competência se limitar aos Estados, o Tribunal tem, ainda assim, tido oportunidade de se pronunciar sobre questões de direitos humanos quando estão em causa a aplicação de convenções sobre direitos humanos, de que é exemplo o caso Actividades Armadas no Território do Congo. Finalmente, o direito à autodeterminação, para cuja afirmação o Tribunal tanto contribuiu, inscreve-se na construção idealista da paz. 
O realismo não deixa, contudo, de perpassar as Nações Unidas, designadamente quando se trata de proteger a soberania dos seus Estados membros. É verdade que os Estados são igualmente um elemento essencial da construção liberal da paz. Porém, quando a soberania estadual é elemento central de análise, são, em parte, tendências realistas que se estão a manifestar.

Afigura-se, pois, possível detectar na estrutura e actividade do Tribunal elementos da narrativa realista. Em primeiro lugar, é particularmente significativo que o Tribunal apenas tenha competência para decidir sobre uma controvérsia se os Estados em questão tiverem aceitado a sua jurisdição. Por outro lado, apesar das decisões tomadas pelo Tribunal no exercício da sua competência contenciosa serem obrigatórias para os Estados, a verdade é que se um deles não quiser cumprir, o mecanismo de execução da sentença é pouco eficaz. Numa tal situação de incumprimento, a outra parte no litígio apenas pode recorrer ao Conselho de Segurança, que não tem sequer um dever de agir. Por exemplo, no âmbito do caso Actividades Militares, a Nicarágua solicitou ao Conselho de Segurança que executasse a sentença do Tribunal que condenava os EUA, obviamente sem sucesso.

A jurisprudência do Tribunal tem também reflectido considerações essencialistas de soberania. No caso Estreito de Corfu, em que estavam em causa considerações relevantes para a segurança da navegação internacional, o Tribunal não teve contudo dúvidas em conferir preponderância à soberania territorial da Albânia, declarando que o respeito pela soberania territorial é um elemento fundamental das relações internacionais.

\section{Conclusão}

O caridoso projecto da paz pelo Direito rege-se por pressupostos que acabam por se tornarem numa visão redutora e até autolimitativa da construção da ordem internacional, composta por insuficiências que podem ser instrumentalizadas. Talvez seja, antes, preferível concentrar a atenção na perspectiva do contributo do Direito para a paz. Um contributo que só pode ser concebível numa construção estruturada e multifacetada e que tenha em conta não apenas a 
realidade que pretende organizar como também os pressupostos da sua própria legitimidade.

A preocupação de que as instituições internacionais sejam instrumentos das potências hegemónicas não pode ser ignorada. O Conselho de Segurança das Nações Unidas induz essa preocupação. O seu imenso poder é gerido pelos "cinco polícias", alguns de estatuto desactualizado, enquanto os países em desenvolvimento não estão suficientemente representados. Contudo, órgãos independentes como o Secretariado ou o Tribunal Internacional de Justiça têm um papel importante de contrabalanço e de influência sobre o poder das soberanias.

O contributo do Tribunal faz-se aplicando o Direito Internacional. Para além de contribuir para a paz através do exercício da sua função de solução jurisdicional de conflitos, o Tribunal tem elaborado construções jurisprudenciais de elementos da paz estruturada que a Carta consagra. Construções essas que, inscrevendo-se na tradição idealista-liberal de paz, não deixam de ser perpassadas por afloramentos do realismo. Um sintoma das dinâmicas que informam as Nações Unidas.

As suas insuficiências constitutivas limitam o seu potencial para contribuir para a paz. Ainda assim, a sua autoridade judicial, a sua relevância doutrinal e as suas consequências políticas fazem do Tribunal um instrumento importante no contributo do Direito para a paz.

\section{Peace in the International Court of Justice Jurisprudence}

\section{Abstract}

The main purpose that led to the creation of the United Nations was peace. The Charter of the United Nations stipulates in its preamble and in Articles 1 and 2 thereof a set of objectives and principles that serve as guidelines for action of the United Nations and of its members. Peace is presented as the structuring and unifying goal of all others. The peace proclaimed in the Charter is thus a broad concept that is not limited to the mere absence of war. Rather, it is a multidimensional 
concept encompassing various elements of action necessary for the maintenance of its inherent condition, such as peaceful coexistence, peaceful settlement of disputes, self-determination, development, promotion and respect for human rights, collective action or respect for sovereignty. The International Court of Justice is the principal judicial organ of the United Nations, thus pertaining to the structure of the organization. Therefore, the Court's work is also devoted to the pursuit of the general objectives of the United Nations, including first and foremost peace as enshrined in the Charter. The present study analyzes the contribution of the activity of the International Court of Justice to peace. Firstly, it will be discussed the role of the Court contextualizing it in the discourse of peace through law. Then it will proceed by reviewing some decisions of the Court seeking to identify outstanding jurisprudential developments concerning peace. From that analysis it is possible to conclude that such developments are mainly inscribed in the liberal-idealist tradition of peace, despite some of them being still laden with outcrops of realism. A symptom of the dynamics that inform the United Nations.

Keywords: Peace. International Court of Justice. Peace through Law. Charter of the United Nations.

\section{Referências}

BAPTISTA, Eduardo Correia. O poder público bélico em Direito Internacional: o uso da força pelas Nações Unidas em especial. Coimbra: Almedina, 2003.

DELAHUNTY, Robert; YOO, John. Peace through Law? The failure of a noble experiment. Michigan Law Review, [S.1.], v. 106, n. 6, p. 923-940. 2008.

DUPUY, René-Jean. Article 2 - Commentaire général. In: COT, Jean-Pierre; PELLET, Alain (Ed.). La Charte des Nations Unies: commentaire article par article. Paris: Economica, 1991. p. 72-77.

FASSBENDER, Bardo. UN Security Council reform and the right of veto: a constitutional perspective. The Hague: Kluwer Law International, 1998. 
HIGGINS, Rosalyn. Message of peace from H.E. Judge Rosalyn Higgins, President of the International Court of Justice. International Court of Justice, 2008. Disponível em: <www.icj-cij.org/presscom/files/9/14759.pdf> Acesso em: 13 dez. 2008.

INTERNATIONAL COURT OF JUSTICE. The Corfu channel case (United Kingdom of Great Britain and Northern Ireland v. Albania): Judgement of April $9^{\text {th }}, 1949$. International Court of Justice Reports, [S.1.], p. 4-169, 1949.

INTERNATIONAL COURT OF JUSTICE. Reparation for Injuries Suffered in the Service of the United Nations: Advisory Opinion of April $11^{\text {th }}, 1949$. International Court of Justice Reports, [S.1.], p. 174-220, 1949.

INTERNATIONAL COURT OF JUSTICE. Legal Consequences for States of the Continued Presence of South Africa in Namibia (South West Africa) Notwithstanding Security Council Resolution 276 (1970): Advisory Opinion of 21 June 1971. International Court of Justice Reports, [S.1.], p. 16-58, 1971.

INTERNATIONAL COURT OF JUSTICE. Western Sahara: Advisory Opinion of 16 October 1975. International Court of Justice Reports, [S.1.], p. 12-69, 1975.

INTERNATIONAL COURT OF JUSTICE. Case concerning military and paramilitary activities in and against Nicaragua (Nicaragua v. United States of America): Judgement of 27 June 1986. International Court of Justice Reports, [S.1.], p. $14-150,1986$.

INTERNATIONAL COURT OF JUSTICE. Case concerning questions of interpretation and application of the 1971 Montreal convention arising from the aerial incident at Lockerbie (Libyan Arab Jamahiriya v. United Kingdom), (Libyan Arab Jamahiriya v. United States of America). Judgements of 27 February 1998. International Court of Justice Reports, [S.1.], p. 9-31; p.115-137, 1998.

INTERNATIONAL COURT OF JUSTICE. Case concerning Armed activities on the Territory of the Congo (Democratic Republic of the Congo v. Uganda). Judgement of 19 December 2005. International Court of Justice. Disponível em: <www.icj-cij.org/docket/files/116/10455.pdf> Acesso em: 20 Dez. 2008.

KELSEN, Hans The Law of the United Nations: a critical analysis of its fundamental problems. London: Stevens \& Sons Limited, 1950.

KELSEN, Hans. Peace through Law. Clark: Lawbook Exchange, 2008. 
KOWALSKI, Mateus. A Carta das Nações Unidas como 'Constituição’ da comunidade internacional. Revista Negócios Estrangeiros, [S.1.], n. ${ }^{\circ}$ 15, p. 31-57. 2009.

LACHS, Manfred. Article 1, paragraphe 1. In : COT, Jean-Pierre; PELLET, Alain (Ed.). La Charte des Nations Unies: commentaire article par article. Paris: Economica, 1991. p. 31-38.

RANDELZHOFER, Albrecht. Article 2, paragraph 4. In: SIMMA, Bruno (Ed.). The Charter of the United Nations: a commentary. Oxford: Oxford University, 2002. v. 1.p. 112-136.

RICHMOND, Oliver. Peace in International Relations. Oxon: Routledge, 2008.

UNITED NATIONS (1985). Programme of the International Year of Peace, adopted by the United Nations General Assembly. Resolution A/RES/40/10 of 11 November 1985. Disponível em: <http://daccess-dds-ny.un.org/doc/RESOLUTION/GEN/ NR0/477/17/IMG/NR047717.pdf?OpenElement> Acesso em: 13 dez. 2008.

UNITED NATIONS (1992). An agenda for Peace: preventing diplomacy, peacemaking and peace-keeping. Report of the Secretary-General. Resolution A/47/277 of 17 June 1992. Disponível em: <http://daccess-dds-ny.un.org/doc/ UNDOC/GEN/N92/259/61/PDF/N9225961.pdf?OpenElement> Acesso em: 13 dez. 2008.

UNITED NATIONS (1999). Declaration and Program of Action on a Culture of Peace, adopted by the United Nations General Assembly. Resolution A/RES/53/243 of 6 October 1999. Disponível em: <http://daccess-dds-ny.un.org/doc/UNDOC/ GEN/N99/774/43/PDF/N9977443.pdf?OpenElement> Acesso em: 13 dez. 2008.

WOLFRUM, Rüdiger. Article 1. In: SIMMA, Bruno (Ed.). The Charter of the United Nations: a commentary. Oxford: Oxford University, 2002. v. 1. p. 39-47.

ZOLO, Danilo. Cosmopolis: prospects for world government. Cambridge: Polity, 1997.

ZOLO, Danilo. Hans Kelsen: international peace through International Law. European Journal of International Law. [S.1.], v. 9, n. ${ }^{2}$, p. 306-324, 1998. 